\title{
HRJ
}

V.2 n.9 (2021)

Recebido: 30/01/2021

Aceito: 06/02/2021

\section{Uso do WhatsApp por uma equipe de Saúde da Família como estratégia para lidar com demandas administrativas}

Samuel de Sousa Alencar ${ }^{1}$

Fernando Aires de Souza ${ }^{2}$

1 Secretaria de Saúde do Distrito Federal. Residente do Programa de Residência em Medicina de Família e Comunidade

2 Secretaria de Saúde do Distrito Federal. Preceptor do Programa de Residência em Medicina de Família e Comunidade

Endereço eletrônico para correspondência: samuelalencarmfc@gmail.com

\section{RESUMO}

Introdução: A atenção primária à saúde é a principal porta de entrada para o SUS e por isso apresenta uma demanda diversificada e quantitativamente alta. As demandas administrativas correspondem a cerca de $20 \%$ de toda demanda da APS, consumindo muito tempo e recursos. Objetivo: Descrever como e em quais circunstâncias a Equipe Cinza da UBS n ${ }^{\circ} 10$ de Ceilândia - DF implementou o WhatsApp como estratégia de atendimento remoto às demandas administrativas, retorno clínico e de aprimoramento da comunicação com os pacientes. Métodos: A equipe se baseou no guia "WhatsApp para Centros de Saúde" elaborado pela Secretaria de Saúde de Florianópolis com algumas adaptações para realidade local. Resultados: Além de observarmos redução na pressão por atendimento na equipe, a ferramenta trouxe diversas possibilidades para a resolução de demandas menos urgentes e vigilância de ações programáticas. A redução da pressão no acolhimento da equipe foi substituída por um alto fluxo de mensagens, o que trouxe algumas dificuldades na organização para as respondê-las. Conclusões: $O$ relato apresentou como o aplicativo de comunicação por mensagens mais utilizado no mundo pode ser um importante aliado na resolução de demandas administrativas e na vigilância dos pacientes já acompanhados pela equipe.

Palavras-chave: Tecnologia em saúde; Atenção primária à saúde; Acesso à saúde; Telemedicina.

\section{Use of WhatsApp by a primary care team as a strategy to deal with administrative demands}

\begin{abstract}
Introduction: Primary health care is the main gateway to SUS, therefore has a diverse and quantitatively high demand. Administrative demands composed about $20 \%$ of all PHC demand, consuming a lot of time and resources. Objective: Describe how and under what circumstances the Gray Team of UBS $n^{\circ} 10$ in Ceilândia - DF realized the implementation of WhatsApp as a strategy of remote attendance to administrative demands, clinical feedback, and to improve communication with its patients. Methods: The team was based on the guide "WhatsApp for Health Centers" prepared by the Municipal Health Department of Florianópolis with some adaptations for the local reality. Results: In addition to observing a reduction in the pressure for service, the tool brought many possibilities for the resolution of no urgent demands and supervision of programmatic actions. The reduction in pressure on the team's reception was replaced by a high flow of messages, which brought some difficulties in the organization to answer them. Conclusions: The report presented how the messaging application most used in
\end{abstract}


the world can be an important ally to resolving administrative demands and monitoring patients already attended by the team.

Keywords: Health technology; Primary health care; Health access; Telemedicine.

\section{INTRODUÇÃO}

A Atenção Primária à Saúde (APS) é o primeiro nível de atenção em saúde sendo composta por ações de saúde individuais e coletivas de promoção à saúde, prevenção de agravos, diagnóstico, tratamento, reabilitação, redução de danos e a manutenção da saúde, desenvolvendo atenção integral com impacto comunitário. É reconhecida como a principal porta de entrada do Sistema Único de Saúde (SUS), e possui como atributos essenciais para o seu funcionamento, o acesso ao primeiro contato, a longitudinalidade, a integralidade e a coordenação do cuidado, gerenciando o trânsito do paciente nos diversos níveis de atenção. ${ }^{1}$

Por desempenhar tamanho papel nos sistemas de saúde, a demanda na atenção primária é bastante diversificada e quantitativamente muito alta. Estima-se que $21,7 \%$ de uma determinada população demandarão atenção numa unidade de cuidados primários em um mês. ${ }^{2}$ Sendo assim, é importante que se compreenda como essas demandas se apresentam na prática diária, a saber, em nove tipos: demanda por condições agudas, demanda por condições crônicas agudizadas, demanda por condições gerais e inespecíficas, demanda por condições crônicas não agudizadas, demanda por enfermidades; demanda por pessoas hiperutilizadoras; demandas administrativas; demanda por atenção preventiva; demanda por atenção domiciliar; e demanda por autocuidado apoiado. ${ }^{3}$

Ao longo de 2020, o Brasil e o resto do mundo passaram por uma histórica crise de saúde devido à pandemia da Coronavirus Disease 2019 (COVID-19), infecção viral do trato respiratório causada pelo vírus Sars-Cov-2, surgido na cidade de Wuhan, na China. Por seu caráter altamente transmissível, o vírus e sua caminhada pelo globo deixaram uma marca particular, a extrema necessidade de distanciamento social. Com isso, os serviços de atenção 
primária, assim como os demais níveis de atenção, tiveram que se reorganizar para reduzir a circulação de pessoas nas unidades de saúde e priorizar esforços para uma situação de calamidade, pois apesar da pandemia, outras demandas que sempre existiram não deixaram de acontecer. $^{7}$

Estudos evidenciam que as demandas administrativas compõem cerca de $20 \%$ de toda demanda da APS, consumindo muito tempo e recursos. ${ }^{4,5,6}$ São demandas não clinicas, como marcação de consultas, laudos médicos, renovação de receitas e análise de resultados de exames. Apesar de menos urgentes, as demandas administrativas ainda são pertinentes, principalmente para pacientes com doenças crônicas, que necessitam de cuidado contínuo, sendo importante o desenvolvimento de mecanismos para atender a estas necessidades. ${ }^{21}$ Para isso, recomendações aos serviços de atenção primária no enfrentamento à pandemia, apontam como um dos pontos chave a necessidade de realizar ações de cuidado à distância, via telefone ou plataformas de internet para diminuir a ida dos usuários as Unidades Básicas de Saúde (UBS). ${ }^{7}$

Assim, a Equipe Cinza da Unidade Básica de Saúde nº 10 da Ceilândia no Distrito Federal (DF) acreditou que com o uso do aplicativo (APP) de mensagens instantâneas WhatsApp (WPP) Business, como ferramenta de comunicação com os pacientes adscritos, conseguiria atender grande parte das demandas administrativas e ainda prestar e receber retornos de caráter evolutivo dos pacientes previamente atendidos presencialmente.

O WPP Business é um aplicativo muito semelhante ao WPP convencional, que se tornou o aplicativo de mensagens mais utilizado no mundo, transformando a forma como as pessoas se comunicam atualmente. No entanto, o APP possui funcionalidades próprias, como envio de mensagens automáticas pré-definidas pelo administrador e melhor organização da lista de conversas. Estas funcionalidades foram desenvolvidas para que empresas pudessem prestar atendimento aos seus clientes de forma rápida e prática desde a retirada de dúvidas até a compra 
de produtos e a assistência pós-venda. Embora não exista relação comercial envolvida, a relação entre uma Equipe de Saúde da Família (eSF) e os pacientes adscritos no território também possui como objetivo a prestação de um serviço, tornando o WPP Business uma ferramenta amplamente aplicável para esta finalidade, algo que já vem proporcionando experiências interessantes em alguns lugares do Brasil. ${ }^{8,9}$

O presente relato tem como objetivo descrever como e em quais circunstâncias a Equipe Cinza realizou a implementação do WPP Business como estratégia de atendimento remoto às demandas administrativas, retorno clínico e de aprimoramento da comunicação com seus pacientes.

\section{MÉTODOS}

Ceilândia é uma região administrativa do DF que surgiu há 49 anos em decorrência da Campanha de Erradicação das Invasões - CEI. Foi um projeto de erradicação de favelas realizado pelo então governador Hélio Prates, com o objetivo de realocar aproximadamente 80 mil moradores de ocupações irregulares que se aglomeravam próximo ao centro da capital. ${ }^{19}$ Hoje com mais de 440 mil habitantes, Ceilândia se tornou a maior região administrativa (RA) do DF. ${ }^{10}$ Desproporcionalmente, essa RA conta com 82 eSF, destas, 20 não possuem um ou mais profissionais mínimos para serem consideradas consistidas. ${ }^{11}$ As equipes estão distribuídas nas 18 UBS de Ceilândia, e garantem cobertura dos serviços da APS para cerca de $54 \%$ de sua população. ${ }^{11}$ A baixa cobertura se torna uma dificuldade ainda maior quando considerada a vulnerabilidade social, classificada como média. ${ }^{12}$ Essa realidade refletiu diretamente nos números da pandemia da COVID-19. Ceilândia liderou absolutamente os números de infectados e mortos pela doença no DF. Até o momento da confecção deste relato foram 29.413 casos confirmados e 748 óbitos. $^{13}$

A UBS n ${ }^{\circ} 10$ de Ceilândia é uma unidade de localização central, próxima a uma estação de metrô, e de vários pontos comerciais, por esta razão apresenta alta circulação de pessoas, 
além disso abrange uma área onde habitam cerca de 28.500 pessoas. ${ }^{14}$ Possui cinco eSF, sendo que uma delas está sem médico há quase dezoito meses e durante a pandemia, assim como muitos outros serviços de saúde, a unidade sofreu com o absenteísmo dos funcionários. Nesse contexto, encontra-se a Equipe Cinza, que é composta por um médico preceptor, dois médicos residentes de medicina de família e comunidade, uma enfermeira, duas técnicas em enfermagem e dois agentes comunitários de saúde (ACS), possuindo 3.166 indivíduos cadastrados, número ainda subestimado quando comparado com a média populacional por equipe na unidade, e quando considerado o fato de possuir apenas dois ACS.

Mesmo antes das medidas restritivas previstas pela pandemia da COVID-19 afetarem os serviços da unidade, a equipe cinza já sofria uma pressão assistencial importante, por isso havia um planejamento para a implementação do WPP como alternativa para lidar com as demandas administrativas e retornos de exames, mas foi o impacto da pandemia na redução dos atendimentos presenciais, que proporcionou tempo hábil para que a equipe estruturasse a ferramenta em Abril de 2020.

Para a implementação do WPP Business, a Equipe Cinza se baseou no guia "WhatsApp para Centros de Saúde" elaborado pela Secretaria Municipal de Saúde de Florianópolis. ${ }^{8}$ Foram realizadas algumas adaptações para realidade local, a começar pela falta de um aparelho celular disponível para uso exclusivo da equipe, portanto instalamos o programa para computador chamado BlueStacks, um emulador - software que reproduz as funções de um determinado ambiente, a fim de permitir a execução de outros softwares sobre ele - do Sistema Operacional (SO) Android. A instalação de programas em computadores da Secretaria de Estado de Saúde (SES) do DF só pode ser realizada pelo setor de Tecnologia da Informação da Superintendência Regional, para isso, solicitamos apoio dos responsáveis para a execução desta primeira parte do processo. Já com o BlueStacks instalado, é possível baixar gratuitamente o aplicativo WPP Business dentro da Google Play Store - loja de aplicativos nativa do SO Android - e utilizá-lo 
exatamente da mesma forma que um smartphone, sendo necessário apenas um chip de qualquer operadora, para que fosse criada e validada a conta dentro do aplicativo, então adquirimos um chip pré-pago e inserimos no aparelho celular pessoal de um dos integrantes da equipe somente para receber o código de confirmação enviado pelo aplicativo. Após esse processo o chip pôde ser removido e não foi mais necessário utilizá-lo. Com o WPP Business instalado, realizamos as configurações iniciais inserindo o nome da equipe, horário de funcionamento, e adicionando uma descrição curta apresentando os integrantes da equipe. Na configuração da mensagem de saudação, - mensagem de texto que é enviada automaticamente quando alguma pessoa entra em contato pela primeira vez - optamos por deixar orientações sobre os horários de funcionamento da equipe, e a solicitação de dados importantes para a identificação, registro e controle dos pacientes, como nome completo, data de nascimento, endereço e número do Cadastro Nacional de Saúde (CNS). Também deixamos claro nesta mensagem que a ferramenta não poderia ser utilizada para atendimentos de urgência e emergência, orientando que, em tais casos, os pacientes deveriam acionar o SAMU ou Bombeiros. Como mensagem de ausência - mensagem de texto enviada automaticamente quando alguém entra em contato fora do horário de funcionamento pré estabelecido nas configurações iniciais - registramos agradecimento pelo contato, informando que em breve seria realizado um contato por parte da equipe, e mantivemos as orientações sobre situações de emergência, bem como reforço sobre os horários de funcionamento.

Uma das intenções da equipe com a implantação da ferramenta foi reduzir a pressão assistencial, principalmente no acolhimento. Para observação simples, fizemos uma comparação do número de atendimentos médicos realizados pela equipe em um mesmo período do ano de 2019 e 2020. A princípio seria utilizado o relatório emitido pelo prontuário eletrônico e-SUS, no entanto, durante a período que seria analisado, enfrentamos dificuldades operacionais com o sistema de prontuário eletrônico que ficou inoperante por aproximadamente 
três meses, por esse motivo, muitos dos atendimentos realizados não tinham sido inseridos eletronicamente ou foram realizados registros tardios, portanto os relatórios poderiam apresentar inconsistências. Então utilizamos os registros presentes em um caderno que fica no acolhimento da equipe há dois anos, onde são anotados os nomes dos pacientes que vão receber atendimento médico diariamente, dessa forma é possível coordenar os atendimentos no dia a dia quando o sistema fica fora do ar. A partir desses registros comparamos os números de atendimentos do mês de outubro de 2019 com o mesmo mês de 2020. A escolha do mês foi proposital, pois foi o período no qual se observou uma queda nos casos suspeitos de COVID19 atendidos na unidade, e o fluxo de pacientes começou a normalizar, apesar de algumas rotinas de rastreio ainda estarem suspensas temporariamente.

Para observar os resultados da ferramenta na pressão por atendimento no acolhimento da equipe, não dispúnhamos de ferramentas objetivas para obtenção de dados de 2019 para comparação, sendo assim, foram consideradas as impressões dos membros da equipe que realizam o acolhimento inicial.

Para iniciar nossa proposta de intervenção fomos aos poucos adicionando os pacientes adscritos nos contatos do aplicativo, fizemos a divulgação do número da equipe através de pequenos cartões de papel contendo informando que a equipe estava disponível para contato pelo aplicativo, também fixamos este cartão na mesa do consultório de atendimento médico, desta forma ao final da consulta ou quando era solicitado algum tipo de retorno evolutivo via $W P P$, o paciente poderia salvar o contato em sua agenda telefônica. Optamos por não deixar o número disponível na porta do acolhimento pois, considerando a grande quantidade de pacientes fora de área que busca atendimento na unidade, e ao contexto de baixa cobertura dos serviços da APS na região, pensamos que isso poderia gerar uma demanda muito grande de pacientes que não seriam de nossa responsabilidade sanitária. 
A implementação da nova ferramenta foi realizada respeitando os princípios bioéticos da beneficência e não maleficência, considerando a autonomia dos pacientes para a utilização presencial ou à distância, e de forma justa disponibilizando livre acesso ao número do WPP da equipe pelos pacientes adscritos no território de referência da equipe. A segurança dos dados dos pacientes contidos nas mensagens é garantida pelo próprio aplicativo com a tecnologia de criptografia ponta a ponta. ${ }^{20}$ Foram consideradas ainda as regulamentações existentes sobre teleatendimentos em saúde. ${ }^{15,16}$

\section{RESULTADOS E DISCUSSÃO}

Ao longo da primeira fase de utilização do APP observamos que muitas demandas nas mensagens, até mesmo as de cunho administrativo, vinham associadas à alguma demanda clínica. Além disso, alguns membros da equipe tiveram dificuldade para utilizar o APP devido à falta de familiarização com ferramentas tecnológicas. Por esses motivos, apenas o preceptor, os residentes, e a enfermeira da equipe assumiram a função de responder as mensagens. Outro motivo importante para funcionar desta forma foi a alta demanda já existente no acolhimento da equipe, função já desempenhada pelos técnicos em enfermagem e por uma dos ACS. Nos períodos comparados, houve queda de 39,7\% no número total de atendimentos médicos. Em outubro de 2019 a equipe realizou cerca de 20 a 25 atendimentos por turno, já no mesmo mês em 2020 esses atendimentos caíram para 15 a 20 atendimentos. É possível que o medo de se contaminar em uma unidade de saúde e as orientações para evitar esses ambientes tenha sido o principal fator para tamanha redução. Tentou-se minimizar essa influência analisando um período no qual o fluxo de pessoas na UBS estava normalizando, no entanto não foi possível quantificar o efeito exclusivo da adoção do WPP. Em relação à pressão por atendimento no acolhimento da equipe, a percepção de todas as integrantes que desempenham essa função foi unânime, afirmando uma redução, principalmente para a necessidade de mostrar resultados de exames ou marcar consulta. Também relataram que por terem a opção de passar o contato do 
$W P P$ da equipe, se sentiram mais confortáveis em comunicar a alguns pacientes que não seria possível atendê-los no mesmo dia.

Foram registrados vários elogios à equipe por parte dos pacientes tanto para a gestão da unidade quanto diretamente aos profissionais do acolhimento. Não foram obtidos resultados sobre os atendimentos realizados pela enfermeira, o que limita a avaliação geral dos atendimentos da equipe. A redução observada na demanda foi substituída por outra proporcionalmente elevada com as mensagens de texto no aplicativo, assim, algumas mensagens acabaram acumulando, e com o aumento no número de mensagens não respondidas, a equipe percebeu que o tempo que estava sendo dedicado para responder as mensagens não estava sendo suficiente. Desta forma, os médicos e a enfermeira da equipe se organizaram em escala composta por períodos de uma hora durante os turnos da manhã e da tarde, nos quais estariam exclusivamente respondendo as mensagens, o que proporcionou mais fluidez nas respostas. Ainda assim, algumas mensagens demoravam mais de 24 horas para serem respondidas e geraram algumas reclamações, portanto seria interessante para a equipe capacitar todos os integrantes para manusearem a ferramenta, melhorando a distribuição das tarefas.

Demandas como solicitação de marcação de consultas, funcionamento da sala de vacina, marcação de exames, entre outras, se repetiram diversas vezes entre as mensagens recebidas. Para lidar com isso, elaboramos respostas padrões para as perguntas mais frequentes e configuramos como mensagens rápidas, - utilidade do aplicativo que permite o registro de mensagens pré definidas que podem ser encontradas rapidamente através de um atalho personalizado - assim, conseguimos respondê-las em menos tempo. A organização em uma única via de acesso das demandas que permitem certa espera para serem resolvidas possibilitou a otimização do tempo de atendimento.

O APP foi muito utilizado pela equipe para fazer a vigilância das gestantes que realizavam pré-natal. Toda semana, durante a reunião de equipe, realizávamos busca ativa das 
gestantes faltosas o que facilitou bastante as remarcações. Por esse motivo, foram o grupo de pacientes que mais utilizou o $W P P$, não só para as demandas relacionadas a gravidez, mas também para relatar queixas de familiares, abrindo o alcance da ferramenta para mais pessoas. Posteriormente, após o parto seguiram utilizando o aplicativo para se comunicarem com a equipe e trazer as demandas referentes às suas crianças. A equipe avaliou positivamente o resultado da assistência às gestantes pelo APP devido ao recebimento de vários elogios através das mensagens, portanto pretendemos realizar a mesma vigilância com outras ações programáticas como a puericultura.

O uso do WPP também complementou alguns atendimentos presenciais, evitando novas frequentações dos pacientes à UBS. Um exemplo muito comum nos atendimentos na APS, o paciente recém chegado no território, ou que está há algum tempo sem acompanhamento, que na consulta comenta sobre alguma prescrição antiga ou exame complementar já realizado antes mas que não levou naquele dia. Nestes casos o paciente era orientado a enviar uma fotografia do documento em questão para o WPP da equipe para que pudéssemos registrar no prontuário posteriormente. Também auxiliou na reavaliação de lesões de pele quando o profissional solicitava que o paciente enviasse uma fotografia mostrando a evolução da lesão. Uma estratégia semelhante passou a ser utilizada em relação aos resultados de exames complementares menos urgentes como os de rastreamento ou de controle para pacientes com doenças crônicas compensadas. Os pacientes eram orientados a entrar em contato via WPP em cinco dias após a realização do exame, prazo considerado para o processamento do resultado, para que pudéssemos analisar os exames e dar o retorno via mensagem de texto pelo próprio aplicativo, orientando a manutenção dos cuidados, ajuste medicamentoso, ou recomendando comparecimento presencial para reavaliação e repasse de novas condutas. Outro resultado interessante para a prática comunitária foram as proposições dos próprios usuários para utilização da ferramenta, a exemplo, um caso no qual tivemos a necessidade de realizar a dose 
diária supervisionada para o tratamento da tuberculose pulmonar de determinado paciente, e estávamos com limitações devido ao baixo efetivo de ACS, foi então que o próprio paciente propôs o envio de vídeos diários registrando a tomada da dose. Essas e outras tantas possibilidades, convenceram a equipe do quanto a ferramenta se mostrou resolutiva. O uso do WPP também foi de grande valia para lidar com o distanciamento social causado pela pandemia, muitos pacientes preferiam tirar suas dúvidas através do aplicativo para não comparecer à UBS. Considerando que os idosos teriam menos acesso à esta ferramenta por não estarem familiarizados com esse tipo de tecnologia, ${ }^{17}$ os residentes adotaram a estratégia de incentivar que tivessem pelo menos um contato via WPP com algum morador da casa, que participasse do cuidado, para fazer intermediação, e assim conseguirem a assistência à distância, evitando um deslocamento muitas vezes penoso e, devido a faixa etária num contexto de pandemia, arriscado. Foi observado pela equipe que muitos homens jovens passaram a enviar mensagens no aplicativo, o que acabou aproximando-os mais da equipe, já que geralmente esse perfil de paciente não busca serviços de saúde. ${ }^{18}$

No início do mês de novembro de 2020 o computador, onde o WPP da equipe funcionava, apresentou problema técnico grave onde houve dano no disco de armazenamento, fazendo com que se perdessem todas as conversas realizadas com pacientes desde o início das atividades com essa ferramenta até então. Isso prejudicou a obtenção de dados importantes como número de atendimentos realizados via $W P P$, a avaliação precisa dos diferentes tipos de demandas apresentadas no aplicativo, e limitou a obra em grande parte a percepções pessoais compartilhadas entre os membros da equipe.

\section{CONCLUSÕES}

O trabalho com o aplicativo de celular, que mudou a forma com a qual nossa sociedade se comunica remotamente, proporcionou para a equipe cinza a possibilidade de otimizar o atendimento a uma das demandas mais prevalentes na atenção primária, organizando-a em uma 
única via de acesso remoto e de fácil utilização, que possui ampla adesão pela população em geral. O relato mostrou que essa ferramenta pode ser um importante aliado na resolução de demandas administrativas e na vigilância dos pacientes já acompanhados pela equipe. No entanto, devido a alta demanda de mensagens recebidas, são necessários organização e cuidado para que as mensagens não se acumulem e a estratégia seja sustentável. Em se tratando de um relato, esse artigo não possibilita a generalidade dos resultados para outras realidades, portanto os autores se preocuparam em narrar a experiência de forma que os métodos fossem reproduzíveis em outros contextos. São necessários estudos que quantifiquem os atendimentos e descrevam com mais precisão o perfil dos pacientes e das demandas que surgem nas solicitações via WPP para aprimorarmos a forma como organizamos a equipe e o tempo para esse tipo de atendimento.

\section{REFERÊNCIAS}

1. Starfield B. Atenção primária: equilíbrio entre necessidades de saúde, serviços e tecnologia. Brasília: UNESCO/Ministério da Saúde; 2002.

2. Green LA, Fryer GE Jr, Yawn BP, Lanier D, Dovey SM. The ecology of medical care revisited. N Engl J Med. 200;344(26):2021-2025.

3. Mendes EV. A Construção Social da Atenção Primária à Saúde. Brasília: Conselho Nacional de Secretários de Saúde - CONASS; 2015.

4. Landsberg GAP, Savassi LCM, Sousa AB, Freitas JMR, Nascimento JLS, Azagra R. Análise de demanda em Medicina de Família no Brasil utilizando a Classificação Internacional de Atenção Primária. Cien Saude Colet 2012; 17(11):3025-3036.

5. Rodrigues J. Porque consultam os utentes o seu médico de família? Rev Port Med Geral Famil. 2000; 16(6):442-452. 
6. Radaelli SM, Takeda SMP, Gimeno LID, Wagner MB, Kanter FJ, Mello VM, Borges JC, Duncan BB. Demanda de serviço de saúde comunitária na periferia de área metropolitana. Rev Saude Publ. 1990; 24(3):232-240.

7. Engstrom E, Melo E, Giovanella L, Mendes A, Grabois V, Mendonça MHM. Recomendações para a organização da Atenção Primária à Saúde no SUS no enfrentamento da Covid-19. Observatório Covid-19/FIOCRUZ; 2020 Mai. Disponível em:https://portal.fiocruz.br/sites/portal.fiocruz.br/files/documentos/recomendacoes_ap s_no_sus_para_enfrentamento_da_covid-19_versao_leitura_uma_coluna_1_.pdf

8. Secretaria de Saúde de Florianópolis. WhatsApp para Centros de Saúde. [eBook] Florianópolis: Dexpertio; 2020. Disponível em: https://dexpertio.com.br/materiais/ebook-whatsapp-para-centros-de-saude

9. Castro FAG de, Santos ÁO dos, Reis GVL, Viveiros LB, Torres MH, Júnior PP de O. Telemedicina rural e COVID-19: ampliando o acesso onde a distância já era regra. Rev Bras Med Fam Comunidade [Internet]. 24 ${ }^{\circ}$ de junho de 2020 [citado $28^{\circ}$ de janeiro de 2021];15(42):2484. Disponível em: https://www.rbmfc.org.br/rbmfc/article/view/2484

10. IBGE 2018

11. Coordenação de Atenção Primária do Distrito Federal - SES/SAIS/COAPS. Brasília; 2020 Dez.

12. Diretoria de Estudos e Políticas Sociais - Dipos/Codeplan. Índice de vulnerabilidade social do Distrito Federal. Brasília: Governo do Distrito Federal; 2020.

13. Painel COVID-19 no Distrito Federal [Internet]. [acessado em 2021 Jan 28]. Disponível em: https://covid19.ssp.df.gov.br/extensions/covid19/covid19.html\#/

14. Diretoria de Vigilância Epidemiológica - SES/SVS/DIVEP. Brasília; 2018. 
15. Brasil. Parecer CFM no 14/2017. Dispões sobre o uso do WhatsApp em ambiente hospitalar. Conselho Federal de Medicina 2017; 27 abr.

16. Brasil. Ofício CFM no 1756/2020. Dispões sobre o uso da Telemedicina durante a pandemia da Covid-19. Conselho Federal de Medicina 2020; 19 mar.

17. Olson KE, O’Brien MA, Rogers WA, Charness N. Diffusion of technology: frequency of use for younger and older adults. Ageing Int[Internet]. Março de 2011; [citado 28 de Janeiro de 2021] 05; 36(1):123-45. Disponível em: https://pubmed.ncbi.nlm.nih.gov/22685360

18. Guibu IA, Moraes JCGJ, Augusto A, Costa EA, Acurcio FA, Costa KS et al . Características principais dos usuários dos serviços de atenção primária à saúde no Brasil. Rev Saude Publ [Internet]. 13 de novembro de 2017 [citado 28 de Janeiro de 2021]; 51(Suppl 2):17s. Disponível em: http://www.scielo.br/scielo.php?script=sci_arttext\&pid=S0034$\underline{89102017000300306 \& \operatorname{lng}=\text { en }}$.

19. Administração Regional de Ceilândia. A História de Ceilândia. [acessado em: 26 de Janeiro de 2021]; [cerca de 2 p]. Disponível em: http://www.ceilandia.df.gov.br/2019/11/08/a-historia-de-ceilandia/

20. O’Sullivan DM, O’Sullivan E, O’Connor M, Lyons D, McManus J. WhatsApp Doc?. BMJ Innov. 2017 Mar. [acessado em: 25 de Janeiro de 2021]; [cerca de 3 p]. Disponível em :https://doi.org/10.1136/bmjinnov-2017-000239

21. Ministério da Saúde. Cadernos de Atenção Básica - Estratégias para o cuidado da pessoa com doença crônica. Brasília, 2014. 